Article

\title{
The Role of Planning in Minimizing the Negative Impacts of Global Climate Change
}

\author{
Bjoern Hagen \\ School of Geographical Sciences and Urban Planning, Arizona State University, Tempe, AZ 85281, USA; \\ E-Mail: bhagen1@asu.edu
}

Submitted: 31 May 2016 | Accepted: 8 July 2016 | Published: 9 September 2016

\begin{abstract}
Climate change is one of the most salient challenges to society, both today and in the near future. Considering the complexity, uncertainties, and scale of possible global climate change (GCC) impacts, there is agreement that urban planning has the capacity to facilitate the development and implementation of adaptation as well as mitigation strategies. The land use planning system provides a framework to reduce greenhouse gas emissions considerably by addressing central issues such as community design, transportation networks and use, and increasing development density. Planning can also play an important role in impacting public behavior, thus slowing the pace of GCC and allowing the development and implementation of adaptation measurements. The purpose of this article is to examine the important role of the planning profession in developing and successfully implementing mitigation and adaptation strategies. There is a growing sense that planning will receive increasing attention as an important policy instrument for addressing both the causes and impacts of climate change. This work also supports the argument that climate action plans can be a vital instrument in confronting the challenges of climate change and that planners need to be more involved in the development and implementation process of such plans.
\end{abstract}

\section{Keywords}

adaptation; global climate change; mainstreaming; mitigation; urban planning

\section{Issue}

This article is part of the issue "Sustainable Planning and Technologies", edited by Hatem Ibrahim (Qatar University, Qatar), Ahmed Khan (Université Libre de Bruxelles, Belgium), Steffen Lehmann (University of Portsmouth, UK), Dellé Odeleye (Anglia Ruskin University, UK) and Atiq Zaman (Curtin University, Australia).

(C) 2016 by the author; licensee Cogitatio (Lisbon, Portugal). This article is licensed under a Creative Commons Attribution 4.0 International License (CC BY).

\section{Introduction}

A great amount of political intervention, public behavioral change, and support for climate action planning will be necessary in the next decade to mitigate the causes of global warming, predominantly human-induced greenhouse gas (GHG) emissions. As of 2008, more than half of the world's population lives in an urban environment (United Nations, 2015) and the majority of the world's energy consumption either occurs in cities or as a direct result of the way cities function. Cities consume about $75 \%$ of the world's energy and are responsible for more than $71 \%$ of energy related GHG emissions (UN Habitat For A Better Urban Future, 2016). Comprehensive changes in numerous aspects of society and the built-up environment will also be required in order to reduce the effects of global climate change (GCC) that are already unavoidable. These actions, collectively known as adaptation and mitigation of climate change, present a challenge to local decision makers and urban planners. However, the two approaches are not independent and, in fact, mitigation and adaptation are driven by the same set of problems (Smit \& Wandel, 2006) and the more mitigation takes place, the less adaptation will be needed (Huq \& Grubb, 2003).

Considering the complexity, uncertainties, and scale of possible GCC impacts, there is agreement that urban planning has the capacity to facilitate the develop- 
ment and implementation of adaptation as well as mitigation strategies (American Planning Association, 2011). The land use planning system provides the framework to reduce GHG emissions considerably by addressing central issues such as community design, transportation networks and use, and increasing development density (Friesecke, Schetke, \& Kötter, 2012). Planning can also play an important role in impacting public behavior, thus slowing the pace of GCC and allowing the development and implementation of adaptation measures. The highly influential Stern Review (Stern, 2007) argues that planning can be an important tool for promoting private and public investment in locations that are less vulnerable to climate risks. Moreover, planning is distinctively qualified to provide comprehensive and long-term approaches that are required to reduce these vulnerabilities through various land use and infrastructure adjustments, and zoning. Although the discussion about the role of spatial and urban planning for responding to GCC is still in its early stages, there is a growing sense that planning will receive increasing attention as an important policy instrument for addressing both the causes and impacts of climate change (Greiving \& Fleischhauer, 2012; Wamsler, Brink, \& Rivera, 2013).

The way urban environments develop will have an impact on whether or not a low carbon, climate resilient future, and worldwide sustainable development can be achieved. The increasing extreme weather events caused by GCC demand the development of new strategies which improve the resilience of cities and their inhabitants and identify new innovative opportunities for a sustainable development pattern (Jabareen, 2013). Planners have to make sure that new developments and long-term infrastructure such as commercial and residential buildings, roads and ports, or water and transport networks are constructed to endure possible negative climate impacts and weather hazards. In addition, long-lasting infrastructure also needs to be designed to decrease the energy consumption and GHG emissions of the built environment (Hallegatte, Henriet, \& CorfeeMorlot, 2011).

Therefore, the purpose of this article is to examine the important role of the planning profession in developing and successfully implementing mitigation and adaptation strategies. The literature review carried out in the present work emphasizes the important role, responsibilities, and challenges planners face when dealing with the issue of GCC. Throughout this study, only literature from scientific books, peer reviewed journal articles and reports published by research institutes or governmental organizations are considered. With the exception of foundational literature that discusses fundamental concepts related to planning and climate change, the study's literature review focuses on the period between the late 1990s and 2016. Considering the fact that the United States is among the main contributors to GCC and recently witnessed the emergence of planning strategies such as New Urbanism, Smart Growth, and Transit Ori- ented Development, the literature review also focuses primarily on studies carried out in North America. In particular, a combination of terms such as climate change mitigation and adaptation, urban planning, transportation and the built environment, smart growth, new urbanism, transit oriented development, and greenhouse gas emissions were used for the literature search.

By examining mostly journal articles, the literature analysis is presented and organized in different sections. Following an introduction on mitigation and adaptation, particular planning strategies and approaches to reduce the causes and impacts of GCC are discussed. After the planning for mitigation and adaptation sections, the importance of mainstreaming relevant policies is discussed, as are the benefits of climate action plans as a tool for planners to confront the challenges created by GCC. The final part of this paper provides a discussion of the reviewed literature and ends with concluding remarks and an outlook on required future research.

\section{Planning for Mitigation}

Mitigation planning is mainly considered as a tool for influencing energy demand and GHG emissions in two ways: first, through the design of new developments and urban retrofitting, and secondly through policies on location and access (Bulkeley, 2006). Policies include, for example, the promotion of energy efficiency, passive solar gain and advancing renewable energy alternatives. The built environment and urban form significantly influence levels of energy use and, thus, GHG emissions levels, which are the main cause of GCC (IPCC, 2013). A good example for a progressive energy strategy, linking policy and design, can be found in the city of Freiburg, Germany. The city's strategy to reduce GHG emission consists of three pillars: a) energy saving, b) efficient technology, and c) renewable energy sources (Beatley, 2012; Gregory, 2011). As a result, the city enforced strict design standards for new buildings in 1992, and also invested in insulation and energy retrofits, which has reduced heat oil consumption significantly. Furthermore, Freiburg relies heavily on combined heat and power plants (CHP), which produce both electricity and heat by capturing the waste heat from electricity production. Regarding renewable energy, Freiburg is, in particular, known for having solar installations throughout the city and the energy plus homes in the Vauban neighborhood.

The term 'urban form' describes the spatial characteristics of fixed elements within a metropolitan region (Anderson, Kanaroglou, \& Miller, 1996). Urban form not only includes land uses and their structure and density, but also the spatial design of the transport and communication infrastructure. As noted by Calthorpe (2011), however, urban design is still often neglected as a strategy against GCC. Moreover, he argues that without more sustainable development patterns, mitigating and adapting to global climate change will be impossible. Nevertheless, urban planning has recently been receiving in- 
creasing attention as an instrument for changing urban forms and promoting a more sustainable development pattern. In the past two decades, planning approaches such as New Urbanism, Traditional Neighborhood Design, Smart Growth, Sprawl Repair and Transit Oriented Development have emerged as alternatives to conventional patterns of urban design. Influential literature and advocates of these planning strategies (Newman, Beatley, \& Boyer, 2009; Tachieva, 2010) argue for introducing design features that, when implemented, will reduce energy and car use. These principles comprise the mixing of land uses, compact urban development, walkable neighborhoods, and transportation alternatives, as well as shorter trip lengths and improved accessibility. Starting in the mid-1970s, one of the first cities in the United States that implemented New Urbanism and Transit Oriented Development principles was Sacramento, California. During this time the city started to develop the Capitol Area Plan which established a light rail transit system, a mix of low-rise and high density housing, the restoration of historic buildings, and the construction of new energy-efficient office buildings (Calthorpe, 2011). Today, the efforts undertaken by the city of Sacramento can be considered a prime example of the type of urbanism needed to mitigate climate change. Overall, the existing literature underscores the importance of urban form and household energy use, as well as underlining the increasing responsibility of planners for advocating and implementing more sustainable development patterns, which reduce energy uses and thus GHG emissions (Fraker, 2013; Newman \& Kenworthy, 2015).

\subsection{Urban Form and Transportation}

In one of the first studies addressing the link between land use and transportation and its implications for planners, Kelly (1994) argues that decisions made in the transportation sector influence land use patterns and vice versa. This conclusion was based on a comprehensive literature review covering six decades of research, examining case studies, practical recommendations, and mainly theoretical work. Due to the strong focus on theoretical literature and thus the lack of available data on the relationship between urban form and travel behavior, the study did not allow the validation of the benefits of the theories presented, designing ideas, and policies. Early studies, which were mostly theoretically-based, were not able to show conclusively to what degree particular settlement structures and urban design features systematically reduce car use and daily miles travelled and thus reduce transportation related GHG emissions. Instead, uncertainties and conflicting conclusions remained (Berman, 1996; Cervero \& Gorham, 1995).

An example of this is the study by Crane and Crepeau (1998), which emphasized the uncertainty regarding the relationship between urban form and transportation. Acknowledging the growing popularity of smart growth and similar planning concepts as tools to reduce the negative environmental impacts of urban development, the authors emphasized that the impact of any specific neighborhood feature on travel behavior is still based on unproven hypotheses. The literature review published by Crane in the year 2000 followed up on the question of whether neighborhood design can improve traffic conditions (Crane, 2000). Here, the author argues that the literature has made significant progress in terms of identifying key questions to understand the complex relationship between urban form and transportation. Crane's study suggested that while the body of research is improving, strong evidence that transitor pedestrian-oriented neighborhood plans-can effectively reduce the use of the automobile is still missing. Nevertheless, Crane acknowledged that existing research (Boarnet \& Crane, 2001) at the time provided some evidence that certain street patterns along with commercial concentration result in fewer non-working automobile trips. Still, the scientific foundation for accepting that urban design can change travel behavior had not yet been fully accomplished.

Among the first publications that showed significant progress in reducing he uncertainty regarding the impact of land use on travel behavior was Ewing, Bartholomew, Winkelman, Walters, and Anderson's (2008) study. The research focused on two important questions in terms of successfully mitigating global warming. First, to what degree can vehicle miles traveled be reduced through compact development patterns instead of continuing urban sprawl? Secondly, what is the impact of less vehicle miles traveled on the total amount of GHG emissions within the transportation sector? Based on multiple studies and methodologies, the authors concluded that the average vehicle miles traveled could be reduced by $20 \%-40 \%$ by implementing design principles and guidelines which foster more compact development. Ewing, et al. (2008) pointed out that a 7-10\% reduction in GHG emissions could be achieved by the year 2025 through appropriate urban form. The article also emphasized that a compact development pattern would not only reduce GHG emissions in the transportation sector, but also reduce the amount of harmful emissions in other sectors of the economy. Although a 7-10\% reduction does not seem much at first, it is worth the effort for a number of reasons. First, the authors discount improved vehicle and fuel technology alone. They argue that if the current development pattern is continued, every improvement in technology will be offset by the growth of car dependency and vehicle miles traveled. Khattak and Rodrigues (2005) also concluded that traffic reduction can be achieved in well-planned and developed neighborhoods that follow the guidelines advocated by New Urbanism, Smart Growth, or Transit Oriented Development.

Another key publication on the relationship between the built environment and transportation was the $\mathrm{Na}$ tional Research Council's (2009) report Driving and the Built Environment: The Effect of Compact Development 
on Motorized Travel, Energy Use, and $\mathrm{CO}_{2}$ Emissions. The study concluded that a higher residential and employment density probably results in less vehicle miles traveled. In the best case scenario, a reduction of $25 \%$ could be achieved. However, the report only expected a reduction of about $5 \%$ to $12 \%$ vehicle miles traveled. Furthermore, the paper confirmed that compact mixed-use development can directly and indirectly reduce energy consumption and $\mathrm{CO}_{2}$ emissions. The authors pointed out numerous obstacles that make the implementation of a more sustainable land use development pattern difficult, such as the aversion of many local governments to revising their zoning codes and the lack of power within regional governments to regulate land use. Overall, the National Research Council report encourages the implementation of more mixed-use development to reduce vehicle miles traveled, energy consumption, and GHG emissions. However, the report is not without criticism. Scholars such as Ewing, Nelson and Bartholomew (2009) criticized the projection by the National Research Council as too conservative. Instead, they points to their own studies, summarized in the book Growing Cooler (Ewing, Winkelman, Walters, \& Chen, 2008). The results in this book suggest a $20 \%$ to $40 \%$ reduction of vehicle miles travelled through compact development. Moreover, the publication identifies five key factors of urban design that reduce travel and emphasize the important role of urban planning in decreasing energy use and GHG emissions. These guidelines are now often referred to as the 5Ds (Hamin \& Gurran, 2009; National Research Council, 2009). The first $D$ represents density, which captures the level of population and employment per square mile or per developed acre. The second $D$ is diversity, and is an indicator for the mix of different land uses in an area. Design, the third $D$, addresses the features enabled by the overall neighborhood layout and street design that enhance walkability and bicycle-friendliness. The fourth $D$ stands for destination accessibility. This indicator assesses the effort needed for the population to travel between trip origins and desired destinations. The final indicator and fifth $D$ is the distance of transit, which examines the accessibility of transit.

Social aspects and public attitudes towards living in traditional, more walkable, and transit-oriented neighborhoods also need to be considered when discussing the benefits of specific urban designs for reducing energy use in the transportation sector. Lund (2006) conducted a study, surveying households located in communities characterized by transit-oriented development. Lund pointed out that households moved into these neighborhoods on the basis of a wide range of motivations. A significant factor, however, is that one third of the households surveyed named access to transit as one of the top reasons for living in a transit-oriented development. Other responses that were equally or even more frequent pointed to lower housing costs and the overall quality of the neighborhood. Lund argued that people's attitude and lifestyle preferences influence signifi- cantly their choice of residential location. However, the author stated that it was not clear to what extent those attitudes and preferences impacted the resident's daily routine, such as travel behavior, compared to the opportunities provided by their household's location. Nonetheless, the results of the study showed that residents of transit-oriented developments use public transit more often when compared to people living elsewhere.

\subsection{Urban Form and Household Energy Use}

Holden and Norland (2005) pointed to population density as well as size, age and type of housing as key factors in energy demand. Their study showed that with regard to compact urban form, the type and grouping of housing are likely to be the two most important land use characteristics impacting energy consumption related to heating and cooling. The authors also concluded that multi-family housing is more energy efficient than single dwellings. Residents of larger and older buildings in particular had a higher energy demand than their counterparts living in smaller, but also newer units based on the latest building designs, materials, and technologies. These findings were echoed by Ewing and Rong (2008) as well as by Lehman (2015). Furthermore, the energy required for establishing electricity transmission and distribution is higher in sprawling communities than in highdensity neighborhoods. In the United States alone, the residential sector is responsible for more than $20 \%$ of the country's energy consumption (Ewing \& Rong, 2008). Thus, retrofitting buildings to improve energy efficiency, assigning higher energy standards in new developments, or releasing stricter insulation regulations will all be important tools for planners hoping to decrease energy demand in the building sector and mitigate GCC. A recent study by Liu and Sweeney (2012) examined the relationship between household energy demand and urban form using both energy and land use models. The results supported the findings of previous studies, showing that residential urban form has a significant impact on energy demand. Furthermore, type, age and size of housing and household density were once again identified as key characteristics for reducing energy consumption when cooling or heating households. Moreover, the output of the computer models suggest that compact cities can decrease energy consumption by up to 16.2 percent per household compared to cities which are characterized by urban sprawl with low density developments.

Guided by the question of whether the physical form of today's cities impacts private energy use at home, the study by Ko (2013) provides an extensive review of the existing literature in the fields of architecture and planning. In particular, the study examines the relationships between particular urban forms and energy use primarily for space conditioning (heating and cooling). The urban form elements considered included: a) size and type of housing; b) density with regard to physical compactness, dwelling units, and population; c) community lay- 
out such as street orientation or building configuration; and d) natural elements in the form of trees and other vegetation. With regard to housing type and size, the study confirmed the results of previous research, arguing that low-density settlements with predominantly detached housing use more energy for cooling and heating as multi-unit developments or attached housing. Furthermore, the author demonstrates that the increase in the average house size since 1978 has outpaced any improvement in energy efficiency over the same time span. In terms of density, research suggests that in densely populated inner city areas with mainly multi-family housing, the energy consumption per capita is lower than in the single family-dominated housing of the suburbs (Pitt, 2013). However, more research is needed to fully evaluate the potential trade-offs between high-density developments in different climates. The aspect ratio of building height to street width can have a significant impact on energy use. On the one hand, in hot and dry conditions studies show that narrow twisting streets aligned with the usual wind direction and compactly spaced buildings with staggered heights are most energy efficient (Aggarwal, 2006). This type of aspect ratio supports natural ventilation, while simultaneously diverting strong winds and enabling buildings to provide shade for each other. On the other hand, in cold regions compact form can lead to an increase in energy use for heating due to reduced solar access (Steemers, 2003). In addition, compact urban environments can minimize heat loss from buildings and contribute to the urban heat island effect (Krishan, Baker, Yannas, \& Szokolay, 2001) as well as limiting the opportunities for on-site solar energy generation (Cheng, Steemers, Montavon, \& Compagnon, 2006). Another key element affecting energy use for space conditioning addressed by Ko (2013) is the community layout. Solar neighborhood guidelines, for example, advocate an east-west street orientation, which would result in lots being oriented north-south. This would allow more south-facing buildings to maximize solar access in a neighborhood. Again, more research and data are needed to quantify the impact of urban form elements on residential energy use.

Another important dimension of urban form and household energy is the presence of natural systems within the settlement structure. In respect to plant and surface coverage, research often points to the beneficial impacts of trees and urban parks in reducing energy consumption for heating and cooling. Tree planting efforts can improve the control of solar access, evapotranspiration, natural ventilation, and the urban heat island effect (Maimaitiyiming et al., 2014; McPherson \& Simpson, 2003; Middel, Häb, Brazel, Martin, \& Guhathakurta, 2014). The climate inside parks tends to be cooler than in its urban surrounding. Studies have proven that the vegetated park is a cool patch in the built-up city. This phenomenon is often referred to as the "Park Cool Island" effect or "Oasis Effect" (Saito, Ishihara, \& Katayama, 1990). Observations conducted by Spronken-Smith and
Oke (1999) also confirmed that vegetated urban parks are often cooler than their surroundings. Various climate studies related to urban parks show the magnitude and spatial distribution of the park cool island effect. Upmanis, Eliasson and Lindqvist (1998) analyzed and compared parks in different cities throughout the world and noted that the cold park climate often extends beyond the park and therefore influences the temperature in surrounding urbanized areas. Yu and Hien (2006) examined the thermal benefits of city parks. In order to analyze the cooling effect of green areas, they measured temperatures at vegetated and non-vegetated locations throughout the city. Notable cooling effects of parks were reported within the vegetated urban areas, but also in the surrounding urban environment. Thus, lower temperatures in the park and in the nearby built environment prove the cooling impact of city parks. According to their research and simulations, arranging green urban parks and additional evaporating surfaces throughout the whole urban settlement structure can alter the energy balance of an entire city. As a result, the urban temperature will be reduced because more heat can be dissipated (Yu \& Hien, 2006). Meier (1991) also acknowledges the energy-saving potential of trees and other landscape vegetation. Meier's (1991) study points out that vegetation can mitigate urban heat islands directly by shading heatabsorbing surfaces, and indirectly through evapotranspiration cooling. Furthermore, the author's research shows that vegetation consistently lowers wall surface temperatures by about seventeen degrees Celsius and reduces air conditioning costs by 25 to 80 percent. Moreover, urban parks support city ventilation, which is an important aspect for the mitigation of the urban heat island effect, especially during the night. The park breeze plays an important role in city ventilation. The theory of park breeze is based on temperature differences as a driving force for the divergent outflow of cool air at a low level (Oke, 1988).

\section{Planning for Adaptation}

Even in the case of successful mitigation, the impact of GCC will continue affecting the least developed countries and poor population the hardest (IPCC, 2013). Rapid population growth in cities, especially in developing countries, paired with the increasing impact of GCC is adding significant pressure on existing infrastructure, and will eventually cause it to fail. This requires institutional, technical, and spatial measures to adapt to the impacts of GCC in urban areas, where most of the world's population lives today (IPCC, 2014). Planning for adaptation, however, is not an easy task. Global climate change is characterized by high levels of uncertaintys and the requirement and adaptation capacity of a region is often difficult to recognize. As a result, there is no single strategy at the local or (inter)national level to adapt to the impact of GCC or reduce the GHG emissions (Biesbroek, Swart, \& van der Knaap, 2009). In terms of adaptation, 
uncertainty results from the nature of GCC itself, its associated extremes, their effects, the vulnerability of systems and regions, conditions that influence vulnerability, and many attributes of adaptation, including the costs, feasibility of implementation, consequences, and effectiveness (Hamin \& Gurran, 2009).

Global climate change adaptation also requires urban planners to more efficiently communicate with policy makers and the public in new and different ways (American Planning Association, 2011). Planners will need new communication tools to explain the possible impact of GCC and to ensure that the public and decisionmakers maintain the focus on long-term adaptation and mitigation responses. Engaging the public to participate in the adaptation and mitigation process is vital to its success. Many people are not aware of the precise nature, causes, and possible negative impact of GCC ( $\mathrm{Ha}-$ gen, 2016; Leiserowitz, 2010). The way the public processes information and new scientific findings regarding GCC has a significant effect on how and to what degree mitigation and adaptation strategies are supported. GCC has to be communicated in a way that motivates the public to change their behavior and support adaptation or mitigation policies (Wolf \& Moser, 2011).

Spatial and urban planning presents a strategic framework in which adaptation, as well as mitigation measures can be integrated as a part of a broader perspective on sustainable development (Uittenbroek, Janssen-Jansen, \& Runhaar, 2013). Due to their expertise in adapting the urban environment to the impact of GCC, urban planners are in a position to usefully engage local stakeholders, policy makers, and decision-makers to advocate for urban adaptation strategies. The following section examines the role of the local planner in terms of adapting the built environment to reduce the impact of the potential hazards of GCC. Based on the existing literature, the question of how planners should think and plan for adaptation, as well as how planners should consider incorporating climate adaptation strategies into existing and new policies are discussed. Any incorporation of climate adaptation strategies should be based on indepth impact assessments or risk analyses considering local circumstances.

\subsection{Vulnerability Assessment}

Different aspects need to be addressed by planners in order to assess the vulnerability of built-up environments to possible GCC risks and impacts. One key aspect of vulnerability assessment, especially for urban planners, is to identify vulnerable populations. Since the poorest countries of the world are those who will suffer disproportionately from its consequences, GCC raises issues of equity and social justice (Grasso, 2007). As seen in the case of Hurricane Katrina in New Orleans, however, not only populations in poor countries are vulnerable to extreme weather events, but also the most disadvantaged in wealthy nations (Van Heerden \& Bryan, 2006).
Although Katrina cannot be linked directly to GCC, it represents the type of GCC impact that we can expect in the future and thus need to be prepared for. However, in order to plan and adapt to such events appropriately, equity issues need to be addressed. Planning and policy approaches need to consider local inequalities and injustice, reflected in disparities in wealth, health, education and job opportunities (Saavedra \& Budd, 2009). Planners are well-suited to the task of overcoming these issues by identifying and addressing the root of inequities, promoting policies to reduce the problem, empowering communities, working across agencies and departments, recognizing and respecting cultural differences, and aiming for strategies for long-term, permanent change (Friesecke et al., 2012; Jabareen, 2013).

In addition, planners need to determine to what degree specific systems such as the transportation infrastructure, the built-up environment, threatened ecosystems, or public health will be affected by the previously assessed impact of GCC. Following the climate impact assessment, the first step in the vulnerability assessment process should be the evaluation of the exposure of specific systems or groups within the population to the impact of GCC (UKCIP, 2010). For example, infrastructure in coastal areas or near rivers might be exposed to flooding due to projected sea level rise or increasing precipitation. As in climate impact assessment, climate models play an increasing role in this part of the vulnerability assessment (Abraham, 2009). Geographical Information Systems (GIS) can produce high resolution maps at the local scale to illustrate the exposure of urban areas to sea level rise or the Urban Heat Island Effect (UHI). Such specific information leads to diminishment of uncertainties and support of urban planners in their development of appropriate adaptation strategies.

Three interrelated factors stand out in the literature with regard to determining vulnerabilities (Lowe, Foster, $\&$ Winkelman, 2009). These factors are exposure, sensitivity and capacity to adapt to the impact of GCC. Sensitivity to this impact refers to the degree to which resources, population, infrastructure, or other important components of the urban environment respond to incremental changes in the impact of GCC. This concept allows urban planners to identify the sectors which will be influenced earliest by GCC and consequently will need to be addressed first by adaptation strategies. According to the IPCC Working Group II (IPCC, 2014), adaptive capacity describes the 'potential or ability of a system, region, or community to adapt to the effects or impacts of GCC. On an urban scale, this means that by increasing their adaptive capacity, settlements are more likely to cope with changes and uncertainties in climate. As a result, a high adaptive capacity also increases the resiliency of cities and encourages sustainable development (Smit \& Wandel, 2006).

The idea of resiliency as a policy and planning goal has its origin in ecosystem theory (Holling, 1973) and is now commonly used in the context of GCC adapta- 
tion (Meerow, Newell, \& Stults, 2016). Resiliency to GCC from a planning perspective can be understood to improve the ability of urban systems to bounce back after suffering a negative environmental event. Since future GCC is already built into the earth's atmosphere and its short-term effects cannot be avoided anymore, thus making adaptation a necessity, it is important that planning strategies not only address the identified vulnerabilities of a city and its population but also improve the ability to recover from negative GCC induced events. Still, the need to adapt to GCC is not fully acknowledged by all countries or administrations (Wamsler et al., 2013). Moreover, the countries that do recognize GCC adaptation as a significant planning challenge have only implemented very few adaptation policies (Carmin, Nadkarni, \& Rhie, 2012; Greiving \& Fleischhauer, 2012). Overall, the important role of urban planning in the success of GCC adaptation is still not recognized strongly enough among policy-makers. Policy action on planning for the adaptation of cities and towns is just now emerging and thus many adaptation strategies have not yet been translated into planning practices. Nevertheless, several adaptation strategies have already been implemented in communities worldwide.

\subsection{Strategy Development}

According to an extensive review of current adaptation practices worldwide (Wamsler et al., 2013), most policies that are currently proposed are quite similar and not highly focused on local circumstances. The most frequently employed measures include updating infrastructure and disaster plans to include and acknowledge projected forecasts for GCC, considering larger floodplains for areas with possible increased storm events and precipitation, establishing wildlife corridors, and adjusting building codes to support more natural cooling while contributing less to the UHI effect (Hamin \& Gurran, 2009). Most adaptation strategies focus on the physical structure of the built environment with the aim of reducing the vulnerability of buildings and infrastructure to the impact of GCC. The main focus of authorities in terms of urban adaptation seems to be the reduction of flood risks, the risk of landslides, extreme temperatures, urban drought and urban heat island effects. In addition, there is a preference for adaptation policies which also have a beneficial impact in terms of GCC mitigation and GHG emissions reduction. This is especially the case in Europe, where so called "climate planning" is an emerging trend which combines GCC mitigation and adaptation (Davoudi, Crawford, \& Mehmood, 2010a).

A major criticism of current adaptation approaches is that most policies address physical factors separately from related non-physical factors (Wamsler et al., 2013). This means that the close interrelationships between the social, cultural, economic, political and institutional characteristics of cities on one hand and the physical features of the urban fabric on the other are not addressed appro- priately. As a result, current policy frameworks do not allow urban planning to show its full potential in terms of GCC adaptation, which can lead to a further reduction in the resilience of cities rather than improving it. As a result, Wamsler et al. (2013) provide a conceptual framework to reduce urban risks through adaptation measures and strategies, while acknowledging the missing links between physical assessment and social/contextual issues. Depending on the local circumstances and the results of previously performed impact and vulnerability assessments, urban planners might need to address various sectors. For example, adaptation strategies might need to consider biodiversity and habitat, infrastructure, rising sea levels, public health, water resources and management, or forestry and agriculture. During the development process of adaptation strategies urban planners need to evaluate possible adaptation options according to their costs, benefits, efficiency, and implementability. They also have to be aware of potential tradeoffs and conflicts with mitigation strategies. For example, on the one hand, mitigation of GHG emissions on an urban scale focuses on densification of the built-up environment to reduce vehicle miles traveled and the energy use of buildings. On the other hand, adaptation strategies often rely on open spaces to address storm water, species migration, urban cooling, and other goals. Thus, planners need to develop strategies that minimize this conflict and find the right balance between minimizing the causes and impact of GCC. Despite the fact that planners are considered well placed to address GCC risks and adaptation, it remains unclear what exactly their role is, how their responsibilities relate to those of city authorities, and how national adaptation policies can be translated into local planning strategies (Greiving \& Fleischhauer, 2012).

\subsection{Mainstreaming}

In order for planners to incorporate climate adaptation strategies successfully, the issue of climate change and adaptation in particular has to be integrated or mainstreamed into existing government policy (Wamsler et al., 2013). The aim of mainstreaming is to make adaptation to climate change a part of other well-established programs. Otherwise, urban planners do not have the tools or the political support necessary to implement the appropriate adaptation measurements into their regular planning routine (Huq \& Reid, 2004). In terms of urban planning, planners need to integrate climate change risks into development policies and patterns. Thus, any decision-making process dealing with urban planning, relevant issues such as urban design, water supply, and capital investments in agriculture, urban form, energy, and transportation, or any other infrastructure should consider its impact on and resilience to climate change. This can only be achieved if adaptation becomes an inherent part of urban planning practices, which requires the suitable use and mixture of a set of different mainstreaming strategies. 
Several measures exist to promote mainstreaming of adaptation, including the integration of climate information into environmental data sets, vulnerability or hazard assessments, broad development strategies, macro policies, sector policies, and development project design and implementation (Huq, Rahman, Konate, Sokona, \& Reid, 2003). Nevertheless, there are also constraints for successfully mainstreaming climate change risks and its impact into development and urban planning. The five major constraints are the relevance of climate change information for development-related decisions, the uncertainty of climate information, compartmentalization with governments, segmentation and other barriers within development-cooperation agencies, and tradeoffs between climate and development objectives (Hay \& Mimura, 2006).

To integrate climate effects and risks into the decision-making process of urban policy and development, many cities have developed Climate Action Plans (CAP) (Basset \& Shandas, 2010). The plans range from theoretical or motivational documents to highly detailed documents stating concrete goals with thoroughly designed methods. The first generation of Climate Action Plans focused mainly on improving municipal operations in terms of energy use and GHG emissions (Millar-Ball, 2010). Today, these plans are also addressing jurisdictionwide policies such as land use planning focusing on supporting public transport, compact development, and green building codes. In general, CAPs seem to get the most support from policy makers if the development strategies provide immediate or highly visible results (Basset \& Shandas, 2010). Climate Action Plans and their recommendations present a great opportunity to change current planning and developments patterns. Climate Action Plans can provide the framework and the political power to change current development patterns, improve the position of the planner in the decisions making process, and establish a sustainable way of living in the future, which reduces vulnerability to GCC and increases the adaptive capacity of communities.

However, so far, planners seem to play only a small role in the development of CAPs. Instead, municipalities tend to rely more on environmental engineering, and environmental departments (Boswell, Greve, \& Tammy, 2011). Furthermore, only a very limited number of completed climate action plans address the need to develop and implement adaptation plans. Considering the type of policies presented in existing CAPs and the lack of adaptation strategies, planners need to take a leading role in the development and implementation process. Planners have the expertise to improve CAPs significantly. Many climate action plans focus on strategies that are already part of various sustainable urban planning practices, such as compact and energy saving development patterns or extensive green spaces throughout neighborhoods. Furthermore, planners have the tools necessary to improve the resiliency of urban environments and improve their adaptive capacity regarding potential negative impacts of GCC.

\section{Discussion}

The existing literature suggests that planning strategies have great potential for achieving significant GHG emission reductions as well as decreasing the vulnerability and increasing the adaptive capacities of urban environments. However, with regard to mitigation, the existing body of knowledge is not sufficient to come to definitive conclusions and more research is needed either to validate the benefits of compact and transit-oriented development patterns, or to avoid unforeseen negative consequences resulting in even higher energy use and GHG emissions. As long as questions remain, reliable predictions of the impact of land use and design strategies on travel behavior will remain elusive. The existing body of knowledge does not suggest that planning approaches implementing a development pattern based on the 5Ds are mislead. Rather, it demonstrates that success in terms of reducing GHG emissions and energy use is not self-evident. Nevertheless, it is undeniable that the built environment is a primary contributor to GCC as current development patterns make driving a necessity in many places, resulting in high energy consumption and GHG emissions. Although the impacts of land use on modal split remains unclear, planners must play a key role in promoting energy efficiency in the existing built environment and changing development patterns, transportation systems, and regulations in ways that reduce GHG emissions. At the very least, planning strategies promoting more sustainable development patterns offer various commuting choices.

Even when the potential risks and impacts are understood, the perceived long timeframe of climate change presents a significant barrier to the development and implementation of place-specific strategies. Nevertheless, more tools, resources, and ongoing efforts are becoming available to planners to provide guidance for adaptation planning. The concept of adaptation is not entirely new. Instead, it includes well-established practices from disaster risk management, coastal management, resource management, spatial planning, urban planning, public health, and agricultural outreach. However, several aspects of GCC adaptation are new. Among the new challenges are unprecedented extreme climate conditions, the rate of change, knowledge and methodological challenges, as well as new actors related to climate-sensitive resources, such as water planners, forest managers, urban and spatial planners, architects, tourism managers, and health care providers (Füssel, 2007).

The diversity of adaptation challenges emphasizes the fact that it is impossible to develop a single and globally applicable approach to assessing, planning, and implementing adaptation measures. Any risk assessment and discussion about adaptation measurements has to allow flexible methodological approaches in order to 
produce knowledge that is relevant in a particular decision context. Therefore, planned adaptation to climate change means foremost the use of information about present and future climate change to examine the appropriateness of current and planned practices, policies and infrastructure.

Traditional approaches such as making decisions based on worst case scenarios do not apply to the highly complex and uncertain issue of climate change. Instead, a more flexible framework is required that allows decision makers to develop strategies based on many different possible scenarios with feedback loops. This approach is referred to as advanced scenario planning and is a key component of the anticipatory governance framework. The concept of Anticipatory Governance can be described as "a system of institutions, rules, and norms that provide a way to use foresight for the purpose of reducing risk, and to increase capacity to respond to events at early rather than later stages of their development" (Fuerth, 2009, p. 29). It presents a new model for decision making while dealing with great uncertainties such as in the case of climate change. Current research suggests that Anticipatory Governance consists of three steps: anticipation and futures analysis, the creation of flexible adaptation strategies, and monitoring and action (Quay, 2010)

Eventually, the role of planners is about giving recommendations regarding who should do what more, less, or differently, and to determine the resources needed. Moreover, planners have to pay close intention to possible trade-offs between the considered adaptation strategy and already-existing mitigation policies. These two response options can sometimes be mutually reinforcing, but they can also work against each other. Thus, the appropriate adaptation strategies have to be determined on a case-to-case basis, taking the local circumstances into consideration as best possible (Hagen, 2016).

\section{Concluding Remarks and Outlook}

Policy makers, decision makers, and planners agree that mitigating GHG emissions and adapting the built environment to cope with the possible negative consequences of GCC are among the most difficult and important challenges faced by the planning profession today (Davoudi, Crawford, \& Mehmood, 2010b). The increasing awareness of GCC is not only increasingly dictating the sustainable development debate, but is also supporting the critiques of the current predominant development patterns characterized by urban sprawl, separation of uses, and the necessity of owning and operating a private automobile. The need for planners addressing alternative development strategies on different scales and in different places is increasing (Liu \& Sweeney, 2012). The available scientific data emphasizing the complexity, uncertainty and irreversibility of GCC in the near future is also impacting the nature and framing of spatial planning. Planners need to be more involved in the development and implementation process for climate policies and action plans. As a result, planners will be expected to resolve or even overturn short-term and long-term development expectations. Their work will be increasingly guided by questions such as what low carbon, 'climate proof' settlement will look like in terms of urban form and infrastructure; what barriers there will be to effective planning for such development; what the implications for governments will be, from transnational to local levels, and what the relationship between these levels will be; and who will bear the risk and what will the implications be for equity and social development.

Furthermore, as emphasized by Bulkeley (2006), climate change is a global public good that includes complex planning issues that not only exceed the traditional planning framework, but also the policy objectives of local authorities. One of the main issues is the limited availability of climate change impact data at the regional and local scale. Unfortunately, existing models predominantly provide insights only in terms of average changes in climate parameters on a very large geographical scale and over a long time frames. Likewise, compared to mitigation policies which are easy to assess by measuring the change of GHG emissions over time, measuring the effectiveness of adaptation planning, which focuses on avoiding future negative effects of climate change, is much more difficult. The effectiveness of adaptation strategies is still influenced by the high level of uncertainty. More research is needed to improve understanding of the multifaceted relationships between important issues such as energy demand and consumption, land use changes and climate change. It will take an interdisciplinary approach-in which planners will play an important role-to fully understand the environmental, urban, and social problems caused by climate change.

\section{Conflict of Interests}

The author declares no conflict of interests.

\section{References}

Abraham, J. (2009). Southwest climate change network: Assessing climate impacts. Tucson, AZ: The University of Arizona.

Aggarwal, R. (2006). Energy design strategies for citycenters: An evaluation. Paper presented at the $23 \mathrm{rd}$ Conference on Passive and Low Energy Architecture, Geneva, Switzerland.

American Planning Association. (2011). Policy guide on planning \& climate change. Washington, DC: American Planning Association.

Anderson, W. P., Kanaroglou, P. S., \& Miller, E. J. (1996). Urban form, energy and the environment: A review of issues, evidence and policy. Urban Studies, 33(1), 7-36. doi:10.1080/00420989650012095

Bassett, E., \& Shandas, V. (2010). Innovation and climate action planning. Journal of the American 
Planning Association, 76(4), 435-450. doi:10.1080/ 01944363.2010 .509703

Beatley, T. (2012). Green cities of Europe: Global lessons on green urbanism. Washington, DC: Island Press. doi:10.5822/978-1-61091-175-7

Berman, M. A. (1996). The transportation effects of neo-traditional development. Journal of Planning Literature, 10(4), 347-363. doi:10.1177/ 088541229601000401

Biesbroek, G. R., Swart, R. J., \& van der Knaap, W. G. M. (2009). The mitigation-adaptation dichotomy and the role of spatial planning. Habitat International, 33(3), 230-237. doi:10.1016/j.habitatint.2008.10.001

Boarnet, M. G., \& Crane, R. (2001). Travel by design: The influence of urban form. New York: Oxford University Press.

Boswell, M. R., Greve, A. I., \& Tammy, L. S. (2011). Local climate action planning. Washington, DC: Island Press.

Bulkeley, H. (2006). A changing climate for spatial planning. Planning Theory \& Practice, 33(2), 203-214.

Calthorpe, P. (2011). Urbanism in the age of climate change. Washington, DC: Island Press. doi:10.5822/ 978-1-61091-005-7

Carmin, J., Nadkarni, N., \& Rhie, C. (2012). Progress and challenges in urban climate adaptation planning: Results of a global survey. Cambridge, MA: MIT.

Cervero, R., \& Gorham, R. (1995). Commuting in transit versus automobile neighborhoods. Journal of the American Planning Association, 61(2), 210-225. doi:10.1080/01944369508975634

Cheng, V., Steemers, K., Montavon, M., \& Compagnon, R. (2006). Urban form, density and solar potential. Paper presented at the 23rd Conference on Passive and Low Energy Architecture, Geneva, Switzerland.

Crane, R. (2000). The influence of urban form on travel: An interpretive review. Journal of Planning Literature, 15(1), 3-23. doi:10.1177/08854120022092890

Crane, R., \& Crepeau, R. (1998). Does neighborhood design influence travel? A behavioral analysis of travel diary and GIS data. Transportation Research Part D, Transport and Environment, 3(4), 225-238. doi:10.1016/S1361-9209(98)00001-7

Davoudi, S., Crawford, J., \& Mehmood, A. (2010a). Climate change and spatial planning responses. In $\mathrm{S}$. Davoudi, J. Crawford, \& A. Mehmood (Eds.), Planning for climate change: Strategies for mitigation and adaptation for spatial planners (pp. 7-18). London: Earthscan.

Davoudi, S., Crawford, J., \& Mehmood, A. (2010b). Planning for climate change: Strategies for mitigation and adaptation for spatial planners. London: Earthscan.

Ewing, R., Bartholomew, K., Winkelman, S., Walters, J., \& Anderson, G. (2008). Urban development and climate change. Journal of Urbanism, 1(3), 201-216. doi:10.1080/17549170802529316

Ewing, R., Bartholomew, K., Winkelman, S., Walters, J., \& Chen, D. (2008). Growing cooler: Evidence on urban development and climate change. Chicago, IL: Urban Land Institute.

Ewing, R., Nelson, A., \& Bartholomew, K. (2009). Response to Special Report 298 Driving and the Built Environment. Unpublished comment. Salt Lake City: University of Utah.

Ewing, R., \& Rong, F. (2008). The impact of urban form on U.S. residential energy use. Housing Policy Debate, 19(1), 1-30. doi:10.1080/10511482.2008.9521624

Fraker, H. (2013). The hidden potential of sustainable neighborhoods: Lessons from low-carbon communities. Washington, DC: Island Press. doi:10.5822/9781-61091-409-3

Friesecke, F., Schetke, S., \& Kötter, T. (2012). Urban planning for climate change: Position Paper of FIF Working Group 8.1. FIG Working Week 2012: Knowing to manage the territory, protect the environment, evaluate the cultural heritage. Rome, Italy.

Fuerth, L. S. (2009). Foresight and anticipatory governance. Foresight, 11(4), 14-32. doi:10.1108/ 14636680910982412

Füssel, H. M. (2007). Adaptation planning for climate change: Concepts, assessment approaches, and key lessons. Sustainability Science, 2(2), 265-275. doi:10.1007/s11625-007-0032-y

Grasso, M. (2007). A normative ethical framework in climate change. Climatic Change, 81(3-4), 223-246. doi:10.1007/s10584-006-9158-7

Gregory, R. (2011) Germany-Freiburg-Green city. The EcoTipping Points Project. Retrieved from www.ecotippingpoints.org/ourstories/indepth/germany-freiburg-sustainabilitytransportation-energy-green-economy.html

Greiving, S., \& Fleischhauer, M. (2012). National climate change adaptation strategies of European states from a spatial planning and development perspective. European Planning Studies, 20(1), 27-48. doi:10.1080/09654313.2011.638493

Hagen, B. (2016). Public perception of climate change: Policy and communication. New York: Routledge.

Hallegatte, S., Henriet, F., \& Corfee-Morlot, J. (2011). The economics of climate change impacts and policy benefits at city scale: A conceptual framework. Climatic Change, 104(1), 51-87. doi:10.1007/s10584010-9976-5

Hamin, E. M., \& Gurran, N. (2009). Urban Form and climate change: Balancing adaptation and mitigation in the U.S. and Australia. Habitat International, 33(3), 238-245. doi:10.1016/j.habitatint.2008.10.005

Hay, J., \& Mimura, N. (2006). Supporting climate change vulnerability and adaptation assessments in the Asia-Pacific region: An example of sustainability science. Sustainability Science, 1(1), 23-35. doi:10.1007/s11625-006-0011-8

Holden, E., \& Norland, I. T. (2005). Three challenges for the compact city as a sustainable urban form: Household consumption of energy and transport in eight residential areas in the Greater Oslo Region. 
Urban Studies, 42(12), 2145-2166. doi:10.1080/ 00420980500332064

Holling, C. S. (1973). Resilience and stability of ecological systems. Annual Review of Ecology and Systematics, 4(1), 1-23. doi:10.1146/annurev.es.04.110173. 000245

Huq, S., \& Grubb, M. (2003). Scientific assessment of the inter-relationships of mitigation and adaptation. Geneva, Switzerland: IPCC Expert Meeting.

Huq, S., Rahman, A. A., Konate, M., Sokona, Y., \& Reid, H. (2003). Mainstreaming adaptation to climate change in Least Developed Countries (LDCS). London: International Institute for Environment and Development.

Huq, S., \& Reid, H. (2004). Mainstreaming adaptation in development. IDS Bulletin, 35(3), 15-21. doi:10.1111/j.1759-5436.2004.tb00129.x

IPCC. (2013). Climate Change 2013: The physical science basis. Contribution of Working Group 1 to the fifth assessment report of the intergovernmental panel on climate change. Cambridge and New York: Cambridge University Press.

IPCC. (2014). Climate Change 2014: Impacts, adaptation, and vulnerability. Contribution of the Working Group 2 to the fifth assessment report of the intergovernmental panel on climate change. Cambridge and New York: Cambridge University Press.

Jabareen, Y. (2013). Planning the resilient city: Concepts and strategies for coping with climate change and environmental risk. Cities, 31, 220-229. doi:10.1016/ j.cities.2012.05.004

Kelly, E. (1994). The transportation land-use link. Journal of Planning Literature, 9(2), 128-145. doi:10.1177/ 088541229400900202

Khattak, A. J., \& Rodriguez, D. (2005). Travel behavior in neo-traditional neighborhood developments: A case study in USA. Transportation Research Part A, Policy and Practice, 39(6), 481-500. doi:10.1016/j.tra.2005.02.009

Ko, Y. (2013). Urban form and residential energy use: A review of design principles and research findings. Journal of Planning Literature, 28(4), 327-351. doi:10.1177/0885412213491499

Krishan, A., Baker, N., Yannas, S., \& Szokolay, S. (2001). Climate responsive architecture: $A$ design handbook for energy efficient buildings. New Delhi, India. Tata, India: McGraw-Hill.

Lehman, S. (Eds.) (2015). Low carbon cities: Transforming urban systems. London and New York: Routledge.

Leiserowitz, A. (2010). Risk perception and behavior. In S. H. Schneider, A. Rosencranz, M. D. Mastrandrea, \& K. Kuntz-Duriseti (Eds.), Climate change science and policy (pp. 175-184). Washington, DC: Island Press.

Liu, X., \& Sweeney, J. (2012). Modelling the impacts of urban form on household energy demand and related $\mathrm{CO} 2$ emissions in the Greater Dublin Region. Energy Policy, 46, 359-369. doi:10.1016/j.enpol.2012.03.070

Lowe, A., Foster, J., \& Winkelman, S. (2009). Ask the cli- mate question: Adapting to climate change impacts in urban regions. Washington, DC: Center for Clean Air Policy Urban Leaders Adaptation Initiative.

Lund, H. (2006). Reasons for living in a transit-oriented development, and associated transit use. Journal of the American Planning Association, 72(3), 357-366. doi:10.1080/01944360608976757

Maimaitiyiming, M., Ghulam, A., Tiyip, T., Pla, F., LatorreCarmona, P., Halik, Ü., . . . Caetano, M. (2014). Effect of green space special pattern on land surface temperature: Implication for sustainable urban planning and climate change adaptation. ISPRS Journal of Photogrammetry and Remote Sensing, 89, 59-66. doi:10.1016/j.isprsjprs.2013.12.010

McPherson, G. E., \& Simpson, J. R. (2003). Potential energy savings in buildings by an urban tree planting programme in California. Urban Forestry \& Urban Greening, 2(2), 73-86. doi:10.1078/1618-866700025

Meerow, S., Newell, J. P., \& Stults, M. (2016). Defining urban resilience: A review. Landscape and Urban Planning, 147, 38-49. doi:10.1016/j.landurbplan. 2015.11.011

Meier, A. K. (1991). Measured cooling savings from vegetative landscaping. Energy Efficiency and the Environment, 4(3), 133-143.

Middel, A., Häb, K., Brazel, A. J., Martin, C., \& Guhathakurta, S. (2014). Impact of urban form and design on mid-afternoon microclimate in Phoenix Local Climate Zones. Landscape and Urban Planning, 122, 16-28. doi:10.1016/j.landurbplan.2013.11.004

Millar-Ball, A. (2010). Where the action is. Planning, 76(7), 17-21.

National Research Council. (2009). Driving and the built environment: The effects of compact development on motorized travel, energy use, and $\mathrm{CO} 2$ emissions: Special Report 298. Washington, DC: National Academy of Sciences.

Newman, P., Beatley, T., \& Boyer, H. (2009). Resilient cities: Responding to peak oil and climate change. Washington, DC: Island Press.

Newman, P., \& Kenworthy, J. (2015). The end of automobile dependence: How cities are moving beyond carbased planning. Washington, DC: Island Press.

Oke, T. R. (1988). Street design and urban canopy layer climate. Energy and Building, 11(1-3), 103-113. doi:10.1016/0378-7788(88)90026-6

Pitt, D. (2013). Assessing energy use and greenhouse gas emissions savings from compact housing: a smalltown case study. Local Environment: The International Journal of Justice and Sustainability, 18(8), 904-920. doi:10.1080/13549839.2012.748724

Quay, R. (2010). Anticipatory governance: A tool for climate change adaptation. Journal of the American Planning Association, 76(4), 496-511.

Saavedra, C., \& Budd, W. W. (2009). Climate change and environmental planning: Working to build community resilience and adaptive capacity in Washington 
State, USA. Habitat International, 33, 246-252.

Saito, I., Ishihara, O., \& Katayama, T. (1990). Study of the effect of green areas on the thermal environment in an urban area. Energy and Buildings, 15(3-4), 493498.

Smit, B., \& Wandel, J. (2006). Adaptation, adaptive capacity and vulnerability. Global Environmental Change, 16(3), 282-292.

Spronken-Smith, R. A., \& Oke, T. R. (1999). Scale modelling of nocturnal cooling in urban parks. BoundaryLayer Meteorology, 93(2), 287-312.

Steemers, K. (2003). Energy and the city: Density, buildings and transport. Energy and Buildings, 35(1), 3-14.

Stern, N. (2007). The economics of climate change: The Stern Review. Cambridge, MA: Cambridge University Press.

Tachieva, G. (2010). Sprawl repair manual. Washington, DC: Island Press.

Uittenbroek, C. J., Janssen-Jansen, L. B., \& Runhaar, H. A. C. (2013). Mainstreaming climate adaptation into urban planning overcoming barriers, seizing opportunities and evaluations the results in two Dutch case studies. Regional Environmental Change, 13, 399411.

UKCIP. (2010). Identifying adaptation options. London: UK Climate Impacts Program.
UN Habitat For A Better Urban Future. (2016). Energy. UN Habitat. Retrieved from http://unhabitat.org/ urban-themes/energy

United Nations. (2015). World population prospects: The 2015 revision, key findings and advance. New York: United Nations, Department of Economic and Social Affairs, Population Division.

Upmanis, H., Eliasson, I., \& Lindqvist, S. (1998). The influence of green areas on nocturnal temperatures in a high latitude city (Göteborg, Sweden). International Journal of Climatology, 18(6), 681-700.

Van Heerden, I., \& Bryan, M. (2006). The storm: What went wrong and why during Hurricane Katrina-the inside story from one Louisianan scientist. London: The Penguin Group.

Wamsler, C., Brink, E., \& Rivera, C. (2013). Planning for climate change in urban areas: From theory to practice. Journal of Cleaner Production, 50(1), 68-81.

Wolf, J., \& Moser, S.C. (2011). Individual understandings, perceptions, and engagement with climate change: Insights from in-depth studies across the world. Wiley Interdisciplinary Reviews: Climate Change, 2(4), 547-569.

Yu, C., \& Hien, W.N. (2006). Thermal benefits of city parks. Energy and Buildings, 38(2), 105-120.

\section{About the Author}

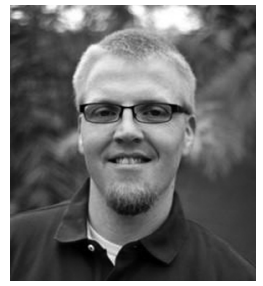

Bjoern Hagen holds a M.Sc. in Spatial and Environmental Planning from the University of Kaiserslautern, Germany, and received his Ph.D. in Environmental Design and Planning from Arizona State University. Dr. Hagen has conducted research in the areas of climate change mitigation and adaptation, public risk perception and risk communication. By studying the nature of public perceptions of global climate change in different countries and over time, his research contributes to improving climate change communication efforts to reduce greenhouse gas emissions and to increase the adaptive capacity and resiliency of urban environments. 